\title{
EVIDENCIAS DE PALEOSISMICIDAD CUATERNARIA EN LOS DEPÓSITOS HIDROMAGMÁTICOS DE LA REGIÓN VOLCÁNICA DEL CAMPO DE CALATRAVA (ESPAÑA CENTRAL)
}

\author{
Elena González \\ Rafael U. Gosálvez \\ Rafael Becerra \\ Estela Escobar \\ Departamento de Geografía y Ordenación del Territorio. Universidad de Castilla-La Mancha \\ Elena.Gonzalez@uclm.es, RafaelU.Gosalvez@uclm.es, Rafael.Becerra@uclm.es, Estela.Escobar@uclm.es
}

\section{RESUMEN}

La paleosismicidad es una herramienta indispensable en el cálculo del riesgo sísmico, proporcionándonos información a lo largo de todo el Holoceno. El objetivo de este trabajo es dar a conocer la existencia de registros de licuefacción-fluidización de edad cuaternaria en depósitos vinculados a erupciones hidromagmáticas en el Campo de Calatrava. Se han reconocido tres tipos de estructuras de deformación que pueden considerarse como sismitas: microfallas, laminación distorsionada y pilares. Conocer el riesgo sísmico y sus efectos inducidos es esencial en la ordenación del territorio.

El objetivo de la paleosismicidad es reconocer e identificar evidencias paleosísmicas que algunos autores (McCalpin, 1996; González-Vallejo, 2004 y Carmona et al., 2011) clasifican como rupturas cosísmicas en fallas superficiales, evidencias generadas sobre la superficie durante el terremoto (procesos de licuefacción y fluidificación reconocibles sobre el terreno como sismitas) y modelados post sísmicos (facetas triangulares y cambios en la red fluvial, entre otros).

La Península Ibérica se localiza en la zona de colisión de las placas Euroasiática y Africana. Su desplazamiento es el responsable de la actividad sísmica del Mediterráneo. España no es un área afectada por grandes terremotos si se exceptúan los que tienen lugar en la falla Azores-Gibraltar (1755 y 1969). Anualmente se registra en torno a 1.200-1.400 sismos en la Península Ibérica, cuya magnitud no suele sobrepasar los 3 grados en la escala de Richter ML (DGPCE, 2012). 
El objetivo de este artículo es presentar la presencia de huellas de licuefacción-fluidización generadas por grandes terremotos, a lo largo del Cuaternario, de los que no se tiene registro histórico o instrumental en sedimentos poco consolidados derivados de la actividad hidromagmática en la Región Volcánica del Campo de Calatrava (RVCC). Esta pasada actividad sísmica debería ser tenida en cuenta de cara a aplicar las normas de construcción sismo-resistentes y para adoptar algunas pautas básicas de planificación y protección ante un posible riesgo sísmico en la región volcánica.

\section{II. ÁREA DE ESTUDIO}

El Campo de Calatrava es una región volcánica localizada en la Meseta Sur en la que la actividad volcánica se ha organizado en ciclos eruptivos de diferente intensidad y localización espacial y temporal a lo largo de 8 ma (Ancochea, 1983). Este volcanismo se asocia a los de La Garrotxa (Cataluña), Macizo Central (Francia) y la región de Eiffel (Alemania) integrados en el volcanismo europeo continental intraplaca (Cebriá \& López-Ruiz, 2010). Las erupciones del Campo de Calatrava se caracterizan por la emisión de magmas alcalinos ricos en $\mathrm{CO}_{2}$, generados a expensas de una anomalía mantélica localizada a poca profundidad bajo la región. Los eventos eruptivos se caracterizan por su baja explosividad en las que se emiten lavas fluidas y piroclastos de caída que dan lugar a la formación de conos de piroclastos, conos y coneletes de spatter y coladas y lagos de lava. La interacción del magma con agua subterránea o subsuperficial ha permitido el desarrollo de violentos episodios explosivos (hidromagmáticos) con la formación de maares y anillos de tobas y el desarrollo de flujos piroclásticos (depósitos de oleadas basales y de explosiones dirigidas), pequeños lahares y mud flow. Más de 300 edificios volcánicos se distribuyen en un área de unos $5.000 \mathrm{Km}^{2}$.

Recientemente, dataciones radiométricas (edades absolutas de 6560 y 6590 BP) de restos orgánicos contenidos en un paleosuelo (González et al., 2007) han confirmado la existencia de eventos freatomagmáticos cuyos depósitos han fosilizado suelos de edad holocena, lo que atribuye al Campo de Calatrava la condición de región volcánica potencialmente activa. (Smithsonian, 2012).

En la actualidad, la actividad residual se caracteriza por la emisión difusa de $\mathrm{CO}_{2}$ de origen magmático cuya procedencia se asocia a la intensa desgasificación de un cuerpo magmático profundo y su ascenso hasta la superficie a través del sistema de fracturas que afecta al basamento paleozoico (Calvo et al., 2010).

\section{METODOLOGÍA}

Se ha llevado a cabo un análisis detallado en nueve localizaciones de depósitos freatomagmáticos, lo que ha sido posible gracias a las obras de construcción y mejora de la red viaria provincial.

Se ha determinado la naturaleza de los depósitos, la localización de su punto de emisión, potencia, superficie ocupada, granulometría y características de las formaciones a techo y muro de los mismos. Los lugares en los que se ha llevado a cabo el estudio de deformación sísmica de los depósitos se localizan al sur y al este de Ciudad Real, bajo las edificaciones de la propia ciudad y en el entorno del Macizo de Calatrava y la Sierra de La Atalaya. 
La zona de trabajo está formada por importantes espesores de depósitos de oleadas piroclásticas y de mud flow que junto a materiales calcáreos, arcillosos y niveles intercalados de volcanitas, constituyen el relleno de las cuencas.

Tradicionalmente se han reconocido tres tipos de deformación que se han interpretado como sismitas (Alfaro et al., 1995): micro fallas, pequeñas fallas verticales formando una densa red y selladas a techo por capas no deformadas, normales e inversas, con saltos centimétricos o milimétricos, interpretadas como el resultado del choque sísmico (González et al., 2010); laminación distorsionada, capas irregularmente deformadas que alteran la disposición originaria del sedimento, con niveles a techo y muro sin deformación, atribuida a fenómenos de licuefacción y fluidificación como consecuencia de fuertes terremotos; y pilares, estructuras de escape de los sedimentos fluidizados o licuefactados que atraviesan y/o deforman las estructuras originales de los niveles superiores, los cuales se asocian también a actividad sísmica de magnitud destacable.

\section{RESULTADOS Y DISCUSIÓN}

\section{Dinámicas hidromagmáticas y depósitos de flujos piroclásticos}

El 50\% de los edificios volcánicos del Campo de Calatrava se han desarrollado en erupciones freáticas y/o freatomagmáticas, constatándose la presencia de fases hidromagmáticas en volcanes puramente magmáticos. La mayoría de estos depósitos no han podido ser datados por lo que su edad relativa se obtiene al comparar su posición con otras formas o formaciones de las que si conocemos su edad. La gran mayoría de estos depósitos se han generado a lo largo del Pleistoceno. Esto les confiere una edad comprendida entre 2,500,000 y 10,000 años.

\section{Deformación de origen sísmico observada en los depósitos hidromagmáticos}

Cuando la energía sísmica y las caracterrísticas del material afectado lo permiten, se han desarrollado las típicas formas (ondulaciones y microfracturación) que se corresponden con fenómenos de licuefacción que abarcan desde la formación en material de cuenca de pequeñas sismitas a grandes diapiros (Lowe, 1976) perforando en toda su potencia los depósitos de los tuff ring. El posible origen sísmico de esta deformación (Montenat, 1993) se apoya en que los materiales situados bajo, y ocasionalmente sobre los depósitos de flujos piroclásticos, no se han visto afectados por las deformaciones y mantienen su posición horizontal original.

Las formas generadas por licuefacción alcanzan especial intensidad en los depósitos de flujo localizados entre Ciudad Real-Miguelturra-Pozuelo de Calatrava, así como en la cuenca de Granátula de Calatrava donde se han señalado potentes procesos de licuefacción afectando a los materiales del anillo de tobas del maar en el que se emplaza el núcleo de población y a los piroclastos de caída del volcán de «Boca del Campo». 


\section{Procesos sísmicos intensos: Diapiros de licuefacción en Calzada de Calatrava}

El depósito estudiado se localiza en Calzada de Calatrava, al sur de la región volcánica. Depósitos de oleadas basales generados en una erupción freatomagmática de edad pleistocena, que se disponen formando un anillo de tobas de 200 metros de afloramiento visible, están atravesados por material areno-limoso que interpretamos como el resultado de la licuefacción de los materiales de cuenca situados bajo los depósitos de oleadas piroclásticas. Este depósito tiene una dirección de $40^{\circ} \mathrm{N}$ y un buzamiento proximal de $25^{\circ}$ que se ve progresivamente alterado por una intensa dislocación, mientras que en las fases distales la inclinación apenas rebasa los $5^{\circ}$ manteniendo su posición original sin ningún tipo de alteración. El afloramiento presenta una típica secuencia rítmica de pulsos explosivos freatomagmáticos. Se distinguen cuatro depósitos principales de oleadas, de una potencia media de $60 \mathrm{~cm}$, con formas de fondo masivas, limitados por bandas de ceniza extremadamente fina y compacta. A partir de un determinado punto el depósito en todo su espesor se ve bruscamente afectado por fallas y por buzamientos muy acusados que llegan a situarlos en posición vertical, hundiendo algunas secciones completas.

De forma abrupta el depósito de flujo piroclástico entra en contacto con materiales arenoso-limosos en cuatro puntos diferentes. Estos materiales rompen y traspasan, distorsionan y verticalizan los depósitos de oleadas situados a techo. Estas intrusiones de los materiales de cuenca se han interpretado como el resultado de un proceso de licuefacción asociado con un movimiento sísmico.

Las cuatro intrusiones tienen unas dimensiones y una morfología similar. El efecto de la licuefacción envía hacia la superficie chorros de agua y material de cuenca (arenas y limos) con una presión capaz de romper los depósitos de las oleadas piroclásticas. La salida de este material causa vaciados parciales que propician el colapso y la inclinación de las diferentes capas hasta producir su verticalidad. En el contacto de ambos materiales (depósitos freatomagmáticos y diapiros de licuefacción) se localizan bandas de material fangoso, carbonatos y formaciones evaporíticas.

\section{Riesgos: Terremotos y emisión de gases magmáticos}

La última erupción del Campo de Calatrava tiene lugar en el Holoceno medio (González et al., 2008), lo que induce a que el área sea considerada potencialmente activa, resaltando sus características eruptivas hidromagmáticas. Depósitos de estos eventos cubren centenares de $\mathrm{km}^{2}$, localizados bajo las zonas urbanas más dinámicas (150.000 personas).

Recientemente se ha probado la existencia de eventos sísmicos significativos (7.5 grados en la escala de Richter) afectando a estos depósitos (Rodríguez \& Barrera, 2002). Las huellas de esta paleoismicidad (Pleistoceno-Holoceno) se han localizado en extensas y numerosas áreas de la región volcánica, mostrando apreciables efectos de licuefacción (González et al., 2010). Ciudades del Bronce Ibérico como «La Encantada» (3500 BC) presentan estructuras dañadas como consecuencia de actividad sísmica (García-Meseguer, comunicación oral).

Si se produjeran eventos sísmicos de las características de los ocurridos en el Cuaternario reciente y en las mismas áreas sus consecuencias podrían afectar a ciudades como Ciudad Real y Puertollano, así como generar un impacto importante en las infraestructuras de comu- 
nicación (autovías, AVE, y aeropuerto) e incluso a áreas industriales de riesgo como el complejo petroquímico de Puertollano.

Las fallas del basamento hercínico situadas al este del Campo de Calatrava presentan un cierto grado de actividad. Se trata de un área de baja sismicidad con terremotos de magnitud entre 1.5 y 2.5 grados en la escala de Richter. Con largos periodos de recurrencia (miles de años) se pueden registrar sismo de magnitud superior al ocurrido el 12 agosto de 2007 (5.1 grados LM, 6 km de profundidad del foco sísmico y 11 segundos de duración) (IGN, 2012). Este terremoto fue sentido en numerosas áreas del centro y sur de la Península Ibérica. Causó daños en edificios próximos a la zona epicentral, así como el hundimiento de la techumbre y daños considerables en muros del teatro Municipal de Almagro.

También las fracturas del zócalo han actuado como salideros para los gases magmáticos $\left(\mathrm{CO}_{2}\right.$ y radon), habiéndose experimentado un notable incremento en la emisión de estos gases, especialmente en el volcán La Sima a partir del sismo del 12 de agosto de 2007(Gosálvez et al., 2010). Este salidero se localiza sobre una fractura de dirección NW/SE en un área de alineamientos volcánicos y de fracturas eruptivas semi activas (Barrera, 2000).

En septiembre de 2007 se llevó a cabo por científicos del ITER (Instituto Tecnológico y de Energías Renovables de Canarias) una campaña de monitoreo de gases magmáticos para evaluar la distribución espacial de la emisión de $\mathrm{CO}_{2}$ por el sistema volcánico calatravo (Calvo et al., 2010). Los resultados han puesto de manifiesto la existencia de una fracción endógena en el $\mathrm{CO}_{2}$ que se emite a la atmósfera en forma difusa. En la actualidad se lleva a cabo un seguimiento continuado de la emisión de gases, dentro del proyecto de investigación titulado: «Evaluación de la emisión de $\mathrm{CO}_{2}$ en el sistema volcánico del Campo de Calatrava. Salideros de Gas de La Sima». Esto permitirá avanzar en la comprensión del comportamiento actual del sistema volcánico del Campo de Calatrava, y su relación con otros sistemas pertenecientes al volcanismo europeo intracontinental.

\section{CONCLUSIONES}

La actividad hidromagmática en el Campo de Calatrava ha sido muy importante en todos los periodos eruptivos de la región. Las ciudades más importantes de la zona están emplazadas en el interior de maares o sobre depósitos hidromagmáticos. Huellas de paleosismicidad se han detectado en numerosas áreas, estando afectados los depósitos por procesos de licuefacción. La última erupción del Campo de Calatrava tiene una edad calibrada inferior a 5.500 años BP (González et al., 2007). Esta erupción se desarrolla en dinámicas freatomagmáticas, emitiendo múltiples oleadas piroclásticas y lahares. Eventos freatomagmáticos afectarían, si se produjeran en la actualidad, a un importante número de personas y centros vitales para el desarrollo del territorio. La actividad sísmica cuaternaria es un hecho probado en numerosas localizaciones del centro y del sureste de España, afectando a depósitos fluviales y lacustres, mientras que en el Campo de Calatrava son los depósitos de flujos piroclásticos los afectados por los esfuerzos sísmicos. El conocimiento del riesgo sísmico y sus efectos es una herramienta esencial en la ordenación del territorio (Mulas de la Peña, 2008).

Recientemente, científicos españoles se han reunido en Guadalajara (Castilla-La Mancha) para determinar el desarrollo de un nuevo mapa de fallas activas en la Península Ibérica. Aunque no existen registros históricos de grandes terremotos, la deformación sísmica que ha 
dejado su huella en sedimentos recientes nos hablan de movimientos sísmicos de magnitud elevada con periodos de recurrencia de miles de años, por lo que no están registrados en la memoria de los habitantes de las regiones afectadas.

\section{AGRADECIMIENTOS}

Este trabajo se ha llevado a cabo dentro del proyecto de investigación: «Evaluación de la emisión de $\mathrm{CO}_{2}$ en el sistema volcánico del Campo de Calatrava. Salideros de Gas de La Sima». Consejería de Educación y Ciencia JCCM. Fondos Europeos FEDER 2010-2012. Agradecemos a Carmen López Moreno, Directora del Observatorio Geodésico Central del Instituto Geográfico Nacional, a sus colaboradores, y al arqueólogo y amigo José Lorenzo García-Meseguer su colaboración y sus valiosas contribuciones de campo a la realización de esta investigación. 